\title{
Family Responsive Policies and Employee Turnover Intentions, the Mediating Role of Work Stress: Perspectives from a Developing Country
}

\author{
Submitted 07/12/20, $1^{\text {st }}$ revision 13/01/21, $2^{\text {nd }}$ revision 16/02/21, accepted 20/03/21
}

Daniel F. Ofori ${ }^{1}$, Emefa Ansah ${ }^{2}$, Majoreen Osafroadu Amankwah ${ }^{3}$

\begin{abstract}
:
Purpose: This study examines the link between organizations' family responsive policies and employee turnover intentions, with work stress as a mediating factor. Previous studies mostly situated in western contexts have focused on aspects of employee turnover intentions. Very few studies have considered family responsive policies and practices as factors in employees' intention to stay or quit a job, particularly in a developing country.

Design/Methodology/Approach: The study adopted a survey approach drawing on responses from a sample of 285 respondents from selected banks. Data were analyzed using Pearson Product moment in SPSS.

Findings: Analyses showed a significant negative relationship between employee turnover intentions and family care services and benefits. Findings also showed a negative relationship between family responsive policies and stress. The work underscores the importance of family-responsive policies in managing turnover intentions of employees. It shows how work stress mediates the relationship between organizations' family responsive policies and employee turnover intentions.

Practical Implications: This study has revealed that these family responsive policies could be the organizations' strategic corporate social responsibility towards their internal stakeholders. Further, organizations desiring to benefit from workplace diversity should aim at implementing these employee maintenance activities to attract competent members from a minority group, especially married women with children who still have the greatest responsibility of managing the family.

Originality/Value: Empirically, this study is the first of its kind in Ghana conducted in a crucial sector of the economy, examining the relationship among family responsive policies, work stress, and turnover intentions.
\end{abstract}

Keywords: Family responsive policies, work stress, turnover intentions, employees, Ghana. JEL codes: $M 12$

Paper Type: Research Paper

\footnotetext{
${ }^{1}$ Department of Organisation and Human Resource Management, University of Ghana, dofori@ug.edu.gh

${ }^{2}$ Department of Organisation and Human Resource Management, University of Ghana, Ansahemefa@yahoo.com

${ }_{3}^{3}$ Majoreen Osafroadu Amankwah (Corresponding Author), Department of Organisation and Human Resource Management, University of Ghana Business School, Legon, Ghana, moamankwah@ug.edu.gh
} 


\section{Introduction}

Changes in lifestyle trends and communications point to a future workforce that is more productive and efficient than before (Attaran, Attaran, and Kirkland, 2019). Modern organizations are therefore required to keep up the pressure for more productivity and efficiency. Thus, employees' work-life balance might be disrupted because of the pressure to respond quickly and efficiently to work. This workplace pressure is negatively related to satisfaction with employees' work (Barber, Conlin, and Santuzzi, 2019). Furthermore, globalization generates new challenges, and accepting these challenges puts heavy work pressure on employees leading to work stress. Some of these challenges include an increase in competition, remaining operational in a larger and diverse market, remaining up to date with knowledge and technology relevant to the organization, etc. Although employees work under this stress, they may not enjoy policies that properly balance work and family life. In fact, Bilal et al. (2010) argued that the absence of family responsive policies in organizations often results in high levels of stress and can rapidly lead to low employee morale, low productivity, and retention problems. Rainayee (2012) further notes that employee turnover intentions, as a work outcome, have become a major corporate challenge in recent times. For instance, Jaharuddin and Zainol (2019) found a direct relationship between work stress and employee turnover intentions.

West (2007) notes that due to the realization that turnover intentions impact business, organizations are beginning to invest in stress reduction efforts such as induction, training, and employee maintenance activities to stand a better chance of retaining their employees. Family responsive practices are programs sponsored by the employer to help employees manage the demands of work and personal life. These policies offer both the employer and employee an opportunity to offer their services and be productive while managing stress and burnout that may emanate from work duties (Jaharuddin and Zainol, 2019). These policies are designed to help employees alleviate the conflict between work and family roles (Choo, Desa, and Asaari, 2016). Most studies on turnover intention have been done in the western context. These studies focused on the various aspects and factors that contribute to employees' turnover intentions (Amponsah-Tawiah, 2015; Rizwan, 2014). Others have focused on organizational responses to employees' intention to quit (Amankwa and AnkuTsede, 2015; Bosomtwe, 2015) and the impact of employees' intention to quit on organizations (Agyemang and Ofei, 2013; Yasmin and Marzuki, 2015).

Researchers have not yet interrogated elements like work-family roles and employee maintenance activities that affect employee turnover intentions. Family responsive policies act as maintenance activities that may influence employees' desire to exit or stay because they have the potential of minimizing stress levels. Theoretically, this study contributes to the extant literature by examining the relationship among all three variables (family responsive policies, work stress, and turnover intentions). Empirically, this study is the first of its kind in Ghana conducted in a crucial sector of the economy. The issues under examination are topical due to the financial sector restructuring exercise that has seen a major upheaval in the Ghanaian banking 
industry over the past three years. The recapitalization exercise, which started in 2017 by the regulatory authority, the Bank of Ghana, has resulted in the closure of several banks and the consolidation (mergers and acquisitions) of others, heightened all levels of all staff in the industry. Against this backdrop, this study examines the relationship between family responsive policies and turnover intentions and the mediating effect of stress on the relationship. This article commences with a literature review situating the relevance of the study (research problem). Furthermore, the literature on job stress, turnover intentions, and family responsive policies is presented, followed by the methodology, findings and discussions. The implications, limitations, and future research conclude.

\section{Literature Review}

\subsection{Research Problem}

A specific challenge confronting most banking firms in the 21st century is the uncertainty in retaining qualified employees due to turnover intentions (Gyensare, 2013). Like most parts of the world, the subject of employee quit intention is no different in Africa. Turnover intentions leading to actual turnovers are also on the rise among the Ghanaian youth. The youth employment network survey indicated that turnover rates appeared to be the most problematic issue in the formal sector (Gyensare et al., 2015). Although turnover intentions in the banking industry in Ghana are unstable, it has many cost implications that affect the industry's growth, especially for evolving banks (Asiedu-Appiah, Mehmood, and Bamfo, 2015). Not only is turnover costly and painful, but it affects productivity (Gyensare, 2013; Saeed, Waseem, Sikander and Rizwan, 2014). If organizations fail to keep their valuable employees, they may spend huge sums of money on exit interviews, replace old staff, train new personnel, and resolve negative allegations leveled against their banks (Asiedu-Appiah et al., 2015). Arvindraj and Shanmugam (2019) outlined job stress, job dissatisfaction, and compensation as factors contributing to employee turnover in the banking sector. The study of Asiedu-Appiah et al. (2015) in Ghana's banking sector showed that most employees with casual employment status are more likely to quit when they get a permanent job in other banks or sectors due to the high level of insecurity. Similarly, younger employees and the newly employed who have less work engagement and are dissatisfied are more likely to vacate their positions of work (Dwomoh and Korankye, 2012). Other factors include personal mobility (change due to a partner's transfer) and long hours of work (Asiedu-Appiah et al., 2015).

The issues enumerated above can create pressure which can have a huge impact on an employees' quit intentions (Shahzad et al., 2011), as employees feel helpless and overburdened when challenged with stress at home and work. For instance, when employees spend long, repetitive working hours combined with stress from home, it results in work-life conflict in the absence of social support. Employees in the banking industry often experience high levels of work-related demands and are therefore at risk of experiencing stress and burnout (Bilal et al., 2010). Stress is a prevalent challenge in modern life, as it tends to disrupt employees' behavior in an 
organization and has a profound effect on destroying organizational performance and efficiency (Miselye, Bagziuniene, and Jakute, 2019). For instance, Jes' (2019) study revealed that South African employees had turnover intentions due to occupational stress. Employees became stressed when they perceived they were not in control. This was found to be a result of imbalances in their personal and professional life. Work stress has been a role conflict (Soelton, 2020; Jaharuddin and Zainol, 2019). According to them, role conflict and work life imbalance led to work stress work-life turn resulted in turnover. The psychological pressure of work, in turn, creates an imbalance between an employee's work and family life. Due to the above, organisations are making efforts to create organizational balance for their employees by ensuring a stress-free environment, which will reduce turnover intentions (AsieduAppiah et al., 2015). Of utmost importance to human resource managers and organizations' corporate sociability is establishing family responsive policies and reducing stress and turnover intentions.

\subsection{Employee Turnover Intentions}

Different authorities have examined turnover intentions in the extant literature. The prevalence of employee turnover, which turnover intentions can cause, is global and no different in West Africa and other parts of the continent (Amankwaa and AnkuTsede, 2015). According to Oluwafemi (2013), just like any other construct, the literature on turnover intention has undergone remarkable evolutionary changes in the past three decades. Turnover intention is an employee's desire to quit their organization (Lee and Jimenez, 2011). It is also an individual's perception of leaving their present job (Liou and Cheng, 2010). Turnover intentions tend to lead to actual turnover: the number of workers leaving in a given period before the expected end of their employment contract (Loquercio, Hammersly, and Emmemns, 2006). Traditional turnover models reveal that intentions to leave are a function of two elements, desirability, and ease of movement (DiRenzo and Greenhaus, 2011; Lee et al., 2008; Steel and Lounsbury, 2009). Desirability indicates the degree of job attractiveness and relates to employee job satisfaction and work stress (DiRenzo and Greenhaus, 2011). Ease of movement is the ease at which an individual could find an alternative job and is a function of job alternatives and organizational inducements (DiRenzo and Greenhaus, 2011).

\subsection{Job Stress}

Stress is part of our daily lives and work and affects individuals and organizations in several ways (Adjei and Amofa, 2014). The upsurge of stress has become a concern to employees and employers in the banking sector (Adjei and Amofa, 2014). The reason being that employees spend most of their lives at work, making the workplace a possible source of stress. Kupriyanov and Zhdanov (2014) conceptualized eustress as positive or good stress against distress which the authors postulated as an antonym for negative stress. This implies that although stress can negatively affect job performance, stress can serve as a source of motivation for task completion (DarteyBaah and Ampofo, 2014). 
However, distress can lead to physiological, psychological, and behavioral difficulties at work. It can affect employees' health and elicit emotions such as anger, depression, anxiety, irritability, and tension (Wani, 2013). According to Gorbatenko and Ramoniene (2013), stress is an adverse phenomenon that can and should be minimized from daily life. Psychological stress can cause an imbalance within work. An imbalance or conflict between work and family domain implies that a negative spillover from one domain will affect the other and vice versa (Hammig, Brauchli, and Bauer (2012). This has a huge influence on an employee's quit intentions (Shahzad et al., 2011). Low control over one's job makes a worker feel overloaded.

When long and repetitive working hours combine with stressors from the family and home, the obvious result is work-life conflict, and more so in the absence of social support. Employees in the banking industry, for example, often experience high levels of work-related demands and are therefore particularly at risk of stress and burnout (Bilal et al., 2010). Work overload has a significant effect on increasing turnover intentions through job satisfaction and work-related stress (Pradma and Salehudin, 2015). However, Higgins et al. (2000) found that the perception of overload and work-life imbalance is the function of job type, a distinction that is clearly relevant for this study considering that the financial services sector is characterized by long work hours and heavy workloads. These stressors in the work environment affect the job satisfaction of employees, which in turn leads to turnover intentions (Applebaum et al., 2010; Chhabra, 2018). Kraemer and Gouthier (2014) add that emotional exhaustion determines turnover intentions.

Excessively long working hours may compel employees to forgo many of their family responsibilities, which imbalances their work and family lives. Since these negative emotional regulations increase stress leading to turnover intentions, employers are now becoming more conscious of implementing policies that streamline their employees' work and family demands. Morrissey and Warner (2011) buttress the above by providing evidence that 70 percent of workers using the employer-provided scheme to reduce family care costs as a component of Family Responsive Policies (FRP) agreed that this arrangement reduced their work-family stress and had a positive impact on their intention to continue working. By extrapolation, this may imply that employees who experience stress due to unavailable family care services and benefits, flexible working conditions, and non-salary benefits are more likely to quit their jobs in the Ghanaian banking industry. Oi-ling and Phillips (2006) also found that the longer the working hours, the higher the perceived stress and turnover intentions. Therefore, finding strategic solutions to work-related stress must be of importance to employees and organizations. This is because formulating policies to resolve stress and safety issues in the working environment, especially in the banks, is key due to their strategic role.

\subsection{Family Responsive Policies}

Family responsive policies cover a range of workplace policies that facilitate the reconciliation of work and family life by ensuring the adequacy of family resources, 
enhancing child development, facilitating parental choice about work and caring, and promoting gender equality in employment opportunities (Francesca, Ana, Jerome, and Frits, 2011; Hakim, 2016; Robert, 2005). Chinchilla and Torres (2006) classified these policies into four: family care services and benefits, flexible working conditions, professional support, and non-salary benefits.

Literature reveals that family responsive policies are in place to help employees achieve work and family life balance and can also be an effective tool for decreasing employees' turnover intentions (Omar, 2010). Yasbek (2004), in a study, found that family responsive policies reduce stress. Ahmad and Omar (2010) found a positive association between family-supportive work culture, affective commitment, and turnover intentions. Similarly, Nijp et al. 's (2012) study provide strong evidence for the positive effects of flexible working conditions on turnover intentions. Furthermore, Bauld, Brough, and Timms' (2009) findings support the above and report that the lack of family care services, a component of family responsive policies, compelled employees to consider moving to a more family-friendly employer.

Consequently, Scholarios and Marks (2004) have indicated that family responsive policies have important consequences for employee attitudes towards their organizations and the lives of employees themselves. Extant literature about family responsiveness and turnover intentions tends to make several assumptions improving an organization's family responsiveness leads to higher productivity and greater company loyalty, and a low level of intent to leave the organization (Moore, 2007). Related reviews by Deery (2008) and Deery and Jago (2009) also found that family responsiveness influences employee's decision to either leave or stay in an organization. Despite the above, a study conducted by McNall et al. (2009) on family responsive policies and turnover intentions showed a conflicting finding.

Unlike some studies that have found that family responsive policies act as a buffering role (Balmforth and Gardner, 2006), other studies have found a significant negative relationship between family responsive policies and turnover intentions (McNall et al., 2009; Wayne et al., 2006). For instance, a meta-analysis conducted by McNall et al. (2009) explored the association between family responsive policies and turnover intentions, found a significant negative relationship between family responsive policies and turnover intentions. The findings implied that family responsive policies only result in feelings and thoughts of contentment but do not affect employees' decisions to leave the organization. Similarly, Ho (2006) found that flexible working conditions do not affect turnover intentions. Based on these findings, we hypothesize the following:

- Family responsive policies will negatively relate to turnover intentions.

- Family responsive policies will negatively relate to employee stress.

- Stress will mediate the relationship between family responsive policies and turnover intentions.

The above hypotheses are summarized and presented in the conceptual framework below. 
Figure 1. Conceptual Framework: Hypothesized Family Responsive Policies Impacting Turnover Intentions of Employees

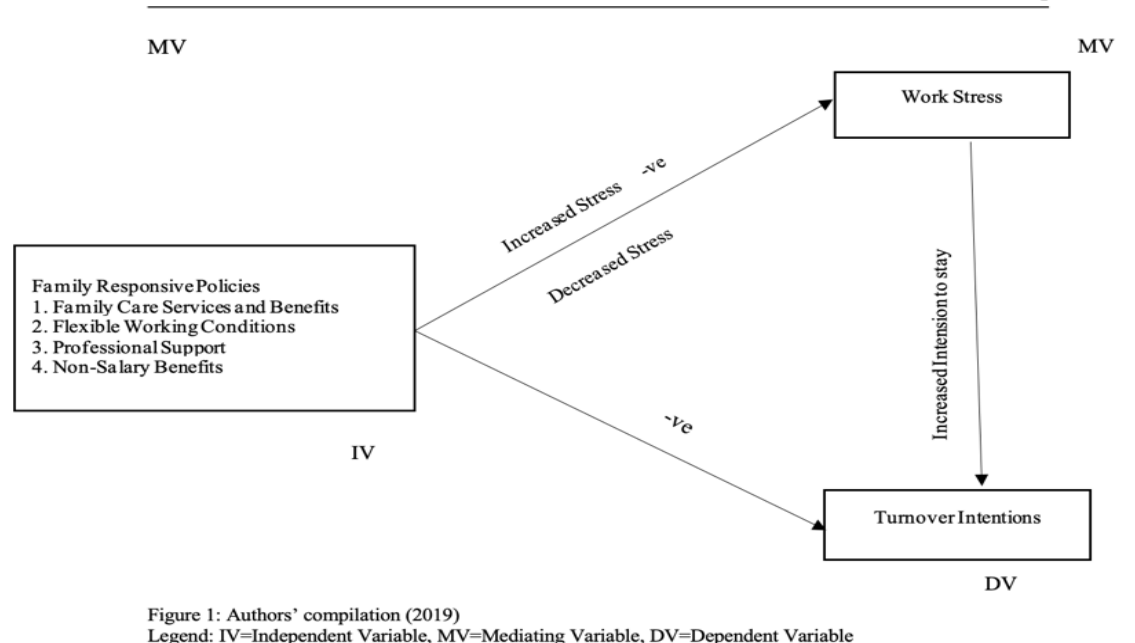

Source: Own creation.

\section{Research Methodology}

\subsection{Design, Sampling Procedure and Sample Size}

This study employed a cross-sectional survey conducted at three different Accra banks, involving 300 workers aged 20 and above. Quantitative data was collected using a multilevel model to address the different levels of employees of each bank. While the purposive approach helped select top banks that agreed to participate in the survey after the initial contact, the convenience approach allowed the selection of respondents who were willing, able, and available to complete the questionnaires at the survey administration time. It also enabled the researchers to ensure that casual and contract employees of the banks were not selected.

Of the three hundred (300) respondents selected from the three banks, 285 responded to the questionnaire representing a $95 \%$ response rate. This high response rate was achieved because the questionnaires were executed directly (not sent blindly or emailed) and several follow-ups. According to Tabahink and Fidell (2007), the sample size for running regression analysis should be $\mathrm{N}>50+8 \mathrm{~m}$, where $\mathrm{N}$ is the sample size, and $m$ is the number of variables in the study. This sample size is deemed adequate and based on the statistical test used in the study, mainly Pearson Moment Correlation and Regression analysis. The sample size needed to be greater than $66(50+8(2))$; hence the sample needed was obtained. The banks selected for the study were active in the Ghanaian financial sector and listed on the Ghana Stock Exchange (GSE). They were made of Bank A (85) respondents, an indigenous Ghanaian-owned bank; Bank B (150) respondents, a Multinational bank headquartered in the United 
Kingdom and with worldwide branches; and Bank C (85) respondents, a Pan- African bank headquartered in West Africa and branches in several African countries.

Regarding respondents' socio-demographic characteristics, sex, age, level of education, marital status, number of children, and position at work are presented. A frequency-percentage analysis of respondents' age distribution as presented in table 1 below across the three banks indicated that most of the respondents were within the age bracket of $30-39$ years, with bank $\mathrm{A}, \mathrm{B}$, and $\mathrm{C}$ recording $55.3 \%, 45.3 \%$, and $52.0 \%$, respectively. It can also be noted that respondents within the age range of 5059 years scored the lowest percentage across the three banks, with bank A, B, and C scoring approximately $8 \%, 5 \%$, and $4 \%$, respectively. On average, these employees were educated, with the majority having a bachelor's degree $54.1 \%, 75.3 \%$, and $44 \%$ for bank A, B, and C, respectively. Regarding their marital status, most were married to bank A, B, and C, recording $64.7 \%, 46 \%$, and 58\%, respectively. All employees' levels were represented, with those in management positions having minimal representation $(11.8 \%, 3.3 \%$, and $18 \%)$ for bank $\mathrm{A}, \mathrm{B}$, and $\mathrm{C}$, respectively.

Table 1. Demographic Profile of Respondents

\begin{tabular}{|c|c|c|c|c|c|c|}
\hline \multirow[t]{2}{*}{ Variable } & \multicolumn{2}{|c|}{ Bank A $(N=85)$} & \multicolumn{2}{|c|}{ Bank B $(N=150)$} & \multicolumn{2}{|c|}{ Bank C $(N=50)$} \\
\hline & $F$ & Percent & $F$ & Percent & $F$ & Percent \\
\hline \multicolumn{7}{|l|}{ Gender } \\
\hline Male & 24 & 28.2 & 76 & 50.7 & 22 & 44.0 \\
\hline Female & 61 & 71.8 & 74 & 49.3 & 28 & 56.0 \\
\hline \multicolumn{7}{|l|}{ Age } \\
\hline $20-29$ & 19 & 22.4 & 62 & 41.3 & 16 & 32.0 \\
\hline $30-39$ & 47 & 55.3 & 68 & 45.3 & 26 & 52.0 \\
\hline $40-49$ & 12 & 14.1 & 13 & 8.7 & 6 & 12.0 \\
\hline $50-59$ & 7 & 8.2 & 7 & 4.7 & 2 & 4.0 \\
\hline \multicolumn{7}{|l|}{ Education level } \\
\hline Diploma/Certification & -- & -- & 6 & 4.0 & 7 & 14.0 \\
\hline Bachelor & 46 & 54.1 & 113 & 75.3 & 22 & 44.0 \\
\hline MA/MBA/MPHIL & 33 & 38.8 & 19 & 12.7 & 16 & 32.0 \\
\hline Professional certification & 6 & 7.1 & 12 & 8.0 & 5 & 10.0 \\
\hline \multicolumn{7}{|l|}{ Marital status } \\
\hline Single & 19 & 22.4 & 79 & 52.7 & 19 & 38.0 \\
\hline Married & 55 & 64.7 & 69 & 46.0 & 29 & 58.0 \\
\hline Divorced & -- & -- & 2 & 1.3 & 1 & 2.0 \\
\hline Widowed & 11 & 12.9 & -- & -- & 1 & 2.0 \\
\hline \multicolumn{7}{|l|}{ Number of children } \\
\hline None & 30 & 35.3 & 67 & 44.7 & 24 & 48.0 \\
\hline One & 22 & 25.9 & 52 & 34.7 & 18 & 36.0 \\
\hline Two & 5 & 5.9 & 9 & 6.0 & 2 & 4.0 \\
\hline Three & 28 & 32.9 & 16 & 10.7 & 4 & 8.0 \\
\hline More than three & -- & -- & 6 & 4.0 & 2 & 4.0 \\
\hline \multicolumn{7}{|l|}{ Position at work } \\
\hline Junior staff & 48 & 56.5 & 100 & 66.7 & 20 & 40.0 \\
\hline Senior staff & 27 & 31.8 & 45 & 30.0 & 21 & 42.0 \\
\hline Management & 10 & 11.8 & 5 & 3.3 & 9 & 18.0 \\
\hline
\end{tabular}

Source: Own creation. 


\subsection{Data Instrument and Measures}

A four-section questionnaire was designed and sent to each responding organization, with the first part assessing biographical data (sex, age, level of education, marital status, number of children, and position at work) of respondents. The second part of the questionnaire elicited information on family responsive policies. The third and fourth sections assessed work-related stress and turnover intentions, respectively. Ethical considerations such as informed consent, anonymity, confidentiality, and respondents responding on their own volition were adhered to.

\subsection{Family Responsive Policies}

Family Responsive Policies were measured using the IESE Family Responsible Employer Index (IFREI, (1999). It is a structured questionnaire of 51 items that assess the development of an organization's Family Responsive Policies and four main parameters: policies, enablers, practices, and culture. This study adapted the subscale of the instrument that measures 31 [policy] items. However, only 29 of the 31 items were used for this study and were categorized into Family Care Services and Benefits, Flexible Working Conditions, Professional Support and Non-salary Benefits.

\subsection{Work Stress}

The Occupational Stress Scale developed by House, McMichael, Wells, Kaplan, and Landerman (1979) was adopted. It measures the frequency with which employees are bothered by stressful occurrences. The scale has five subscales: job responsibilities, quality concerns, role conflict, job versus non-job conflict, and workload. In this study, the subscale that measures job versus non-job conflict was administered as it addressed the research objectives. This subscale had 3 items, and responses were measured using a 5-point Likert-type scale ranging from $1=$ not at all to $5=$ nearly all the time.

\subsection{Turnover Intentions}

Items of the questionnaire were adapted from Bilal et al. 's (2010) instrument, which was used to measure employee turnover intentions in the banking industry in Pakistan due to family-friendly policies existing in the industry. The respondents were asked to indicate their agreement or disagreement with three items on a five-point scale ranging from $1=$ strongly agree to $5=$ strongly disagree. Table 2 shows a summary of descriptive statistics, reliability, and normality coefficients. The scores of the reliabilities ranged from .63 to .90 . Normality is thus achieved per the skewness and kurtosis values.

\subsection{Data Analysis}

The Statistical Package for Social Sciences (SPSS) version 20 was used to analyze the data with a correlation analysis employed to examine relationships between the 
two variables whilst the regression function was used to establish the strength of the relationships. Demographic characteristics were analyzed using descriptive statistics. All formulated hypotheses were tested at the $95 \%$ level of significance or 0.05 alpha level. Correlation and multiple regression analysis were used to test the hypothesized model of family responsive policies and employee turnover intentions in the banking industry. Specifically, it assessed how each independent variable (family responsive policies and stress) would account for a significant variance in the dependent variable (turnover intentions).

Table 2. Means, Standard Deviation, Internal Consistency (Cronbach's alpha) and normality of the study variables

\begin{tabular}{llllllll}
\hline Variable & Minimum & Maximum & Mean & SD & Skewness & Kurtosis & Alpha \\
\hline FCSB & 1.00 & 4.00 & 2.46 & .72 & .219 & -.444 & .633 \\
FWC & 1.00 & 3.00 & 1.42 & .48 & .914 & .121 & .648 \\
PS & 1.00 & 4.00 & 1.89 & .75 & .753 & -.317 & .801 \\
NSB & 1.00 & 4.00 & 2.54 & .76 & .228 & -.793 & .657 \\
WS & 1.00 & 5.00 & 2.95 & .92 & -.040 & -.142 & .649 \\
TI & 1.00 & 5.00 & 3.13 & 1.07 & -.071 & -.809 & .903 \\
\hline
\end{tabular}

Variables $(\boldsymbol{V A}): \mathbf{F C S B}=$ Family care services and benefits; $\boldsymbol{F W C}=$ Flexible working conditions; $\boldsymbol{P S}=$ Professional support $; \boldsymbol{N S B}=$ Non-salary benefits; $\boldsymbol{W S}=$ Work stress and $\boldsymbol{T I}=$ Turnover intention .

Source: Own creation.

\section{Results and Findings}

\subsection{Hypotheses Testing}

All three hypotheses were tested with Pearson product-moment correlation analyses. Before testing each formulated hypothesis, a one-way analysis of variance (ANOVA) was conducted to determine whether the scores from the three banks significantly differed from each other on the dependent variable (i.e., turnover intentions). The ANOVA results confirmed that participants' scores from each bank were significantly different from each other on turnover intentions, $F(2,282)=15.205$, $\mathrm{p}<$ .001 .

Hypothesis one of this study states that family responsive policies will be negatively related to turnover intentions. Regarding participants from bank A, the correlational analysis in Table 3 reveals a significant inverse relationship between family care services and benefits $(r=-.20, p<.10)$; flexible working conditions $(r=-.47, p<.001)$ and turnover intentions as well as a significant positive relationship was observed between non-salary benefits (NSB) and employee turnover intentions $(r=.36, p<$ $.01)$. With respect to bank $\mathrm{B}$, the correlation analysis in Table 3 showed that family care services and benefits $(r=-.27, p<.01)$, flexible working conditions $(r=-.31, p<$ $.001)$, professional support $(\mathrm{r}=-.22, \mathrm{p}<.01)$, and non-salary benefits $(\mathrm{r}=-.28, \mathrm{p}<$ $.01)$ were all significant and inversely related to employee turnover intentions. 
However, only family care services and benefits negatively correlated with employee turnover intention $(r=-.26, p<.10)$ for bank $\mathrm{C}$.

Table 3. Means, Standard Deviations and Pearson's Correlation for Family Responsive Policies and Employee Turnover Intentions for each Bank

\begin{tabular}{llllllllll}
\hline & \multicolumn{3}{l}{ Bank A $(N=85)$} & \multicolumn{3}{c}{ Bank B $(N=150)$} & \multicolumn{3}{c}{ Bank C $(N=50)$} \\
\cline { 2 - 10 } Variables & $M$ & $S D$ & $r_{\text {turnover }}$ & $M$ & $S D$ & $r_{\text {turnover }}$ & $M$ & $S D$ & $r_{\text {turnover }}$ \\
\hline FCSB & 2.13 & .50 & $-.20^{\dagger}$ & 2.64 & .79 & $-.27^{* *}$ & 2.48 & .64 & $-.26^{\dagger}$ \\
FWC & 1.16 & .30 & $-.47^{* * *}$ & 1.55 & .49 & $-.31^{* * *}$ & 1.46 & .51 & -.09 \\
PS & 1.37 & .45 & .04 & 2.14 & .77 & $-.22^{* *}$ & 2.00 & .64 & -.23 \\
NSB & 2.27 & .52 & $.36^{* *}$ & 2.65 & .85 & $-28^{* *}$ & 2.63 & .70 & -23 \\
\hline
\end{tabular}

Note. $\dagger p<.10, * * ; p<.01, * * * p<.001$.

Variables (VA): Family Care Service and Benefit (FCSB), Turnover Intention (TI), Family Responsive Policies (FRP), Non-Salary Benefit (NSB), Flexible Working Conditions (FWC) and Professional Support (PS).

Source: Own creation.

Further, the results in Table 4 indicate that with the exception of professional support (PS) $(r=-.08, p>.05)$, the remaining three; family responsive policies, family care services and benefits $(r=-.17, p<.01)$, flexible working conditions $(r=-.20, p<.01)$, and non-salary benefits $(r=-.12, p<.05)$ were all significantly and negatively correlated with employee turnover intentions across all banks.

Table 4. Pearson's Correlation for Family Responsive Policies and Employee Turnover Intentions Across all Banks

\begin{tabular}{llllllll}
\hline Variables & Mean & SD & FCSB & FWC & PS & NSB & TI \\
\hline FCSB & 2.46 & .72 & -- & & & & \\
FWC & 1.42 & .48 & $.34^{* * *}$ & -- & & & \\
PS & 1.89 & .75 & $.59^{* * *}$ & $.60^{* * *}$ & -- & & \\
NSB & 2.54 & .76 & $.51^{* * *}$ & $.27^{* * *}$ & $.64^{* * *}$ & -- & \\
TI & 3.13 & 1.07 & $-.17^{* *}$ & $-.20^{* *}$ & -.08 & $-.12^{*}$ & -- \\
\hline
\end{tabular}

Note: $* p<.05 ; * * p<.01 ; * * * p<.001$

Variables (VA): Family Care Service and Benefit (FCSB), Turnover Intention (TI), Family

Responsive Policies (FRP), Non-Salary Benefit (NSB), Flexible Working Conditions (FWC) and Professional Support (PS).

Source: Own creation.

The second hypothesis stated that family responsive policies would negatively relate to employee stress. Results presented in Table 5 showed a significant negative relationship between family care services and benefits (FCSB) and work stress ( $\mathrm{r}=$ $.37, \mathrm{p}<.01)$. Also, a significant inverse relationship was found between flexible working conditions (FWC) and work stress $(r=-.44, p<.001)$ for bank A. Hence, it can be inferred from the findings that bank A employees who had higher scores on FCSB and FWC were less likely to experience work stress. For bank B, it was observed that all four family responsive policies: family care services and benefits ( $\mathrm{r}$ $=-.44, \mathrm{p}<.001)$, flexible working conditions $(\mathrm{r}=-.24, \mathrm{p}<.01)$, professional support $(\mathrm{r}=-.19, \mathrm{p}<.05)$ and non-salary benefits $(\mathrm{r}=-.29, \mathrm{p}<.001)$ were negatively correlated with work stress. This may suggest that bank B employees who reported higher 
family-responsive policies were less likely to experience work stress. However, for bank $\mathrm{C}$, only family care service and benefit (FCSB) were significantly and negatively correlated with work stress $(r=-.63, \mathrm{p}<.001)$.

Table 5. Means, Standard Deviations and Pearson's Correlation for Family Responsive Policies and Employee Stress

\begin{tabular}{llllllllll}
\hline & \multicolumn{3}{c}{ Bank A $(N=85)$} & \multicolumn{3}{c}{ Bank B $(N=150)$} & \multicolumn{3}{c}{ Bank C $(N=50)$} \\
\cline { 2 - 10 } Variables & $M$ & $S D$ & $r_{\text {stress }}$ & $M$ & $S D$ & $r_{\text {stres } \S}$ & $M$ & $S D$ & $r_{\text {stress }}$ \\
\hline FCSB & 2.13 & .50 & $-.37 * *$ & 2.64 & .79 & $-.44^{* * *}$ & 2.48 & .64 & $-.63^{* * *}$ \\
FWC & 1.16 & .30 & $-.44^{* * *}$ & 1.55 & .49 & $-.24^{* *}$ & 1.46 & .51 & -.06 \\
PS & 1.37 & .45 & -.15 & 2.14 & .77 & $-.19^{*}$ & 2.00 & .64 & -.24 \\
NSB & 2.27 & .52 & .04 & 2.65 & .85 & $-.29^{* * *}$ & 2.63 & .70 & -.24 \\
\hline
\end{tabular}

Note. ${ }^{*} p<.05 ; * * p<.01 ; * * * p<.001$.

Variables (VA): Family Care Service and Benefit (FCSB), Turnover Intention (TI), Family Responsive Policies (FRP), Non-Salary Benefit (NSB), Flexible Working Conditions (FWC) and Professional Support (PS).

Source: Own creation.

The second aim of the study was to ascertain whether work stress could serve as a pathway through which family responsive policies would relate to turnover intentions. To test this, it was hypothesized that "stress would mediate the relationship between family responsive policies and turnover intentions." This study employed the mediated regression approach by Baron and Kenny (1986) to verify that work stress is a mediation effect on family responsive policies and turnover intentions.

They recommended that mediation regression requires three equations to be calculated, first, the mediator variable is regressed on the independent variable, next, the dependent variable is regressed on the independent variable, and in the final equation, the dependent variable is simultaneously regressed on both the independent and mediator variable. Table 6 presents the three estimated equations for the mediation analysis. In the first equation, work stress was regressed on family care services and benefits, and their relation was found to be significant $(\beta=-.46, p<.001)$, with family care services and benefits explaining $22 \%$ of the variance in work stress.

Next, the turnover intention was regressed on family care services and benefit, and their linkage was also found to be significant $(\beta=-.17, \mathrm{p}<.01)$, with family care services and benefit accounting for as low as $3 \%$ of the variance explained in turnover intentions. Lastly, employee turnover intentions were regressed simultaneously on family care services and benefit and work stress. The association between turnover intentions and family care services and the benefit was not significant $(\beta=.07, p>$ $.05)$. On the contrary, the relationship between turnover intentions and work stress was significant $(\beta=.52, \mathrm{p}<.001)$ in equation three. The independent variable's absolute beta weight in Equation 3 was less than the absolute beta weight in Equation 2, as indicated in Baron and Kenny's (1986) fourth condition for testing mediation analysis. It was concluded that work stress mediated the relationship between family care services and benefit and turnover intentions. Hence, the hypothesis that works 
stress would mediate the relationship between family responsive policies and benefits and turnover intentions was supported.

Table 6. Mediating effect of Work Stress on the relationship between Family Care Service and Benefit and Turnover Intention

\begin{tabular}{lllllll}
\hline Equation & $\begin{array}{l}\text { Dependent } \\
\text { Variable }\end{array}$ & $\begin{array}{l}\text { Independent } \\
\text { Variable }\end{array}$ & $\mathrm{B}$ & $\begin{array}{l}t \text { - } \\
\text { value }\end{array}$ & $R^{2}$ & $F$-statistic \\
\hline 1 & WS & FCSB & $-.46^{* * *}$ & -8.81 & .22 & $77.68^{* * *}$ \\
\hline 2 & TI & FCSB & $-.17^{* * *}$ & -2.96 & .03 & $8.77^{* *}$ \\
\hline 3 & TI & FCSB & .07 & 1.13 & .24 & $44.36^{* * *}$ \\
& & WS & $.52^{* * *}$ & 8.81 & & \\
\hline
\end{tabular}

Note. $N=285 . * * p<.01, * * * p<.001$.

Variables (VA): Family Care Service and Benefit (FCSB), Turnover Intention (TI) and Work Stress (WS)

Source: Own creation.

\section{Discussion and Conclusion}

\subsection{Discussion}

This study examined family responsive policies and turnover intentions and differences in components of family responsive policies and turnover intentions among employees of the three banks. The relationship between all four components of family responsive policies and turnover intentions was tested individually and compositely in the three banks. In bank A, the results indicated that employees who reported higher levels of family care services and benefits and flexible working conditions were less likely to leave the bank, a finding consistent with the study of Nijp et al. (2012), which showed strong evidence for positive effects of flexible working conditions on turnover intentions.

However, the findings of bank A are inconsistent with the findings of Ho (2006), who found that the provision of flexible working conditions did not affect turnover intentions. In bank $\mathrm{C}$, results indicated that among the four components of family responsive policies, family care services and benefits impact intentions to quit than the other three components of family responsive policies. This is consistent with Bauld, Brough, and Timms (2009), Omar (2010), Ahmad and Omar (2010), and Deery and Jago's (2009) findings which reported that lack of family care services as a component of family responsive policies compelled employees to consider moving to a more family-friendly organization. This result suggests that implementing family-responsive policies can positively influence employees' attitudes towards their organizations because employees can balance work and family activities (Scholarios and Marks, 2004). Employee attitude and behavior such as company loyalty is also increased, implying a low intention to quit.

Perhaps the findings are not surprising because the demographic data in Table 3 shows more female than male respondents from banks $\mathrm{A}$ and $\mathrm{C}$, and bank $\mathrm{C}$ also had only $4 \%$ of respondents aged over 50 years. This suggests that younger, female and 
married employees attach more importance to particular family responsive policies than the old, male, and unmarried. Notably, in bank B, all four components of family responsive policies were significantly and inversely related to employee turnover intentions. The difference in the findings may be attributed to family responsive policies such as flexible working conditions, family care provisions, employee assistance, and professional support programs that harm employee turnover intentions, a finding that is inconsistent with Mc Nall et al. (2009).

In examining the relationship between family responsive policies and work stress, a composite investigation of the relationship between the two variables showed that employees who benefited from higher levels of family responsive policies were less likely to experience stress emanating from work in their respective organizations. This finding confirms the study's hypothesized position and supports the findings of Yasbek (2004) that family responsive policies reduce stress. However, results from bank A, the indigenous Ghanaian bank, only showed that employees who benefited highly from family care services and benefits and flexible working conditions were less likely to experience work-related stress, whereas, in bank C, only family care services and benefits predicted employee work stress. On the other hand, results from bank B suggest that all four components of family responsive policies were negatively and significantly related to work stress. This finding is consistent with Shahzad et al. (2011), who found that employees' perceptions that their organization is supportive tend to reduce stress levels.

The study posited that work stress would mediate the relationship between family responsive policies and turnover intentions. Results showed that work stress mediated the relationship between family care services and benefits component of the family responsive policies scale and turnover intentions. Similarly, work stress also mediated the relationship between flexible working conditions component of family responsive policies scale and employees' turnover intentions.

The findings could be attributed to professional support policies that are instituted in some banking organizations. It was also observed that time and stress management and personal or family counseling might have contributed to the mediating role of work stress on the relationship between family responsive policies and turnover intentions. The present study's findings are consistent with other studies by Skinner and Chapman (2013), for instance, which observed a significant negative relationship between family responsive policies and work stress.

Our study also lends support to a study by Morrissey and Warner (2011) in the USA, which found that over 70 percent of workers using an employer-provided scheme to reduce family care costs as a component of family responsive policies agreed that this arrangement reduced their work-family stress and had a positive impact on their intention to continue working. Therefore, this finding tends to reduce the levels of stress and improve employee morale and retention. 


\subsection{Implications for Research and Practice}

This study shows a significant negative relationship between family responsive policies and turnover intentions. Previous studies mostly situated in western contexts have focused on aspects of employee turnover intentions. Very few studies have considered family responsive policies and practices as factors in employees' intention to stay or quit a job, particularly in a developing country context. This study does this by showcasing that to promote successful implementation of family responsive policies and reduce turnover intentions; organizations must broaden their scope of activities within the banking industry in developing countries. Also, organizations need to formulate and implement family-friendly workplace policies that can reduce turnover intentions due to the high-stress levels of employees.

Policies such as family care services and benefits, flexible working conditions, nonsalary benefits, and professional support can increase retention in the banking industry due to their reducing impact on stress. It is possible to assume that many employees might find their organizations do not properly manage this stressful situation. When the organization is reduced, valuable work experience will be lost. Organizations can benefit by adapting these policies to their advantage. This study has revealed that these family responsive policies could be organizations' strategic corporate social responsibility towards their employees. This, therefore, extends the literature on how organizations can be socially responsible to one of their important internal stakeholders. Further, organizations desiring to benefit from workplace diversity should aim at implementing these employee maintenance activities to attract competent members from a minority group, especially married women with children who still have the greatest responsibility of managing the family. These policies will more likely keep them in the labor market

\subsection{Limitations and Suggestions for Future Studies}

The present study did not pay attention to family responsive policy and employee outcomes (e.g., loyalty), future studies could examine these variables. Similarly, the study did not include other stakeholders but relied primarily on information from the banks' employees. Future studies should consider other stakeholders of banks. This study has contributed significantly to the discourse of corporate social responsibility to employees despite its limitations. Specifically, the study has contributed to the extant literature on family responsive policies in developing countries.

\section{References:}

Ahmad, A., Omar, Z. 2010. Perceived family-supportive work culture, affective commitment, and turnover intention of employees. Journal of American Science, 6(12), 839-846.

Amankwaa, A., Anku-Tsede, O. 2015. Linking transformational leadership to employee turnover: the moderating role of alternative job opportunity. International Journal of Business Administration, 6(4), 19. 
Aminah, A.Z.O. 2013. Informal workplace family support and turnover intention: testing a mediation model. Social Behavior and Personality, 20(4), 555-556.

Amponsah-Tawiah, K., Ntow, M.A.O., Mensah, J. 2016. Occupational health and safety management and turnover intention in the Ghanaian mining sector. Safety and Health at Work, 7(1), 12-17.

Applebaum, D., Fowler, S., Fiedler, N., Osinubi, O., Robson, M. 2010. The impact of environmental factors on nursing stress, job satisfaction, and turnover intention. Journal of Nursing Administration, 40(7/8), 323-328.

Arvindraj, A., Shanguan, J.K. 2019. Factors influencing employee turnover intention in banking sector in Penang. Unpublished Thesis, University of Ghana.

Asiedu-Appiah, F., Mehmood, A., Bamfo, A.B. 2015. Work-life balance practices, job performance and turnover intentions. International Journal of Arts \& Science, 8(4), 379-404.

Attaran, M., Attaran, S., Kirkland, D. 2019. The need for digital workplace: increasing workforce productivity in the information age. International journal of enterprise information systems, 15(1), 1-23

Barber, L.K., Conlin, A.L., Santuzzi, A.M. 2019. Workplace tele-pressure and work-life balance outcomes: the role of work recovery experiences. Journal of Stress and Health, 35(3).

Barclays bank limited. 2013. Takoradi. European Journal Business and Innovation Research, 2(2), 55-69.

Baron, R.M., Kenny, D.A. 1986. The moderator-mediator variable distinction in social psychological research: conceptual, strategic, and statistical considerations. Journal of personality and social psychology, 51(6).

Bilal, M., Zia-ur-Rehman, M.R., Raza, I. 2010. Impact of family responsive policies on employees' job satisfaction and turnover intention. Interdisciplinary Journal of Contemporary Research in Business, 2(7), 378-395.

Bosomtwe, T.E. 2015. Employees' perception of organizational merger and its impact on their job satisfaction and turnover intention. Doctoral dissertation, University of Ghana.

Calisir, F., Gumussoy, C.A., Iskin, I. 2011. Factors affecting intention to quit among professionals in Turkey. Personnel Review, 40(4), 514-533.

Chamini, H.G.S., Randeni, R. 2016. Examine the relationship between organizational factors and employee turnover in apparel industry in Sri Lanka. Journal of Business Studies, 5(1), 14-21.

Chhabra, B. 2018. Impact of core-self-evaluation and job satisfaction on turnover intentions: A study of Indian retail sector. Journal of Organizations and Markets in Emerging Economies, 9(2), 292-310.

Choo, J.L.M., Desa, N.M., Asaari, M.H.A.H. 2016. Flexible Working Arrangement toward Organizational Commitment and Work-Family Conflict. Studies in Asian Social Science, 3(1), 21.

Chowdhury, A.A., Nazmul, H. 2017. Factors affecting employee turnover and sound retention strategies in business organization: a conceptual view. Problems and Perspectives in Management, 15(1), 63-71.

Crane, A., Matten, D., Spence, L.J. 2008. Corporate social responsibility: Readings and Cases in a Global Context. London: Routledge.

Dartey-Baah, K., Ampofo, Y.E. 2015. Examining the influence of transformational and transactional leadership styles on perceived job stress among Ghanaian banking employees. International Journal of Business and Management, 10(8), 18333850 . 
Deery, M., Jago, L. 2014. Revisiting talent management work-life balance and retention strategies. International Journal of Contemporary Hospitality, 27(3). 453-472.

Derks, D., Bakker, A.B., Peters, P., van Wingerden, P. 2016. Work-related smartphone use, work-family conflict, and family role performance: The role of segmentation preference. Human Relations, 69(5), 1045-1068. doi: $10.1177 / 0018726715601890$.

Direnzo, M.S., Greenhaus, J.H. 2011. Job search and voluntary turnover in a boundary less world: A control theory perspective. Academy of Management Review, 36(3), 567-589.

Dwomoh, G., Korankye, T. 2012. Labour turnover and its impact on performance of banks in Ghana. European Journal of Business and Management, 4(7), 2222-2839.

Epie, C. 2010. Africa-Specific factors influencing the decision to adopt work-family policies: Exploring the field in Nigeria. Ife Psychologia, 18, 1-18.

Ghosh, D., Gurunathan, L. 2015. Do commitments based human resource practices influence job embededdness, and intention to quit? IIMB Management Review, 27(4), 240-251. doi.org/10.1016/j.iimb.2015.09.003.

Gyensare, M., Otoo, E., Asare, J., Twumasi, E. 2015. Antecedents and consequence of employee turnover intention: Empirical evidence from Ghana. Management Science Letters, 5(8), 781-796.

Gyensare, M.A. 2013. Employee turnover intention. Empirical evidence from the savings and loans companies in Ghana. Unpublished thesis, University of Ghana.

Hakim, C. 2016. Key issues in women's work: Female diversity and the polarization of women's employment. Routledge-Cavendish.

Hammig, O., Brauchli, R., Bauer, G.F. 2012. Effort-reward and work-life imbalance, general stress, and burnout among employees of a large public hospital in Switzerland. The European Journal of Medical Sciences, 3(12). 1-11.

Higgins, E.T. 2000. Making a good decision: Value from fit. American Psychologist, 55(11), 1217.

Hofmann, V., Tokburger-Sauer, N.E. 2017. The impact of emotional labor on employee' work-life balance perception and commitment: A study in the hospitality industry. International Journal of Hospitality Management, 65, 47-58. doi.org/10.1016/j.ijhm.2017.06.003.

Idris, M.A., Dollard, M.F., Winefield, A.H. 2011. The effect of globalization on satisfaction in Malaysian workplaces. Journal of Occupational Health, 53(6), 447-454. Doi: https://doi.org/10.1539/joh.11-0035-FS

Jaharuddin, N.S., Zainol, L.N. 2019. The Impact of work-life balance on job engagement and turnover intention. The South East Asian Journal of Management, 13, 108118.

Jain, N., Bhatt, P. 2015. Employment preferences of job applicants: unfolding employer branding determinants. Journal of Management Development, 34(6), 634-652. doi.org/10.1108/JMD-09-2013-0106.

Kim, Y., Gao, F.Y. 2013. Does family involvement increase business performance? Familylongevity goals moderating role in Chinese family firms. Journal of Business Research, 66. 265-274.

Kraemer, T., Gouthier, H.J.M. 2014. How organizational pride and emotional exhaustion explain turnover intentions in call centers. Journal of Service Management, 25(1), 125-148.

Kupriyanov, R., Zhdanov, R. 2014. The Eustress concept: Problems and outlooks. World Journal of Medical Sciences, 11(2), 179-185. 
Lee, G., Jimenez, B.S. 2011. Does performance management affect job turnover intention in the federal government? The American Review of Public Administration, 41(2), 168-184.

Michel, R.D.J., Michel, C.E.J. 2015. Work Schedule Flexibility, Work-Family Enrichment and Job Satisfaction. Journal of Behavioral Sciences, 25(1), 76-90.

Miselye, M., Bagdziuniene, D., Jakute, V. 2019. Job requirements, resources, and proactive behavior at work: the role of work engagement and stress. Journal of Organizations and Markets in Emerging Economies, 59, 8-22.

Morrissey, T.W., Warner, M.E. 2011. An Exploratory Study of the Impacts of an EmployerSupported Child Care Program. Early Childhood Research Quarterly, 26(3) 344354.

Mowday, R.T., Porter, L.W., Steers, R.M. 2013. Employee-Organization Linkages: The Psychology of Commitment, Absenteeism, and Turnover. Academic Press.

Nijp, H.H.M., Beckers, D.G.J.P., Geurts, S.A.E.P., Tucker, P.P., Kompier, M.A.J.P. 2012. Systematic review on the association between employee work time control and work-non-work balance, health and well- being, and job-related outcomes. Scandinavian Journal of Work, Environment and Health, 38(4), 299-313.

Omar, M.K. 2010. Work status congruence, work-related attitudes, and satisfaction towards work-life balance. International Review of Business Research Papers, 6(1), 145156.

Pradana, A., Salehudin, I. 2015. Work overload and turnover intention of junior auditors in Greater Jakarta, Indonesia. The South East Asian Journal of Management, 9(2), 108-124.

Qureshi, I.M., Iftikhar, M., Zaman, K. 2013. Relationship between job stress, workload, environment and employees' turnover intentions: What we know, what should we know. World Applied Sciences Journal, 23(4). 764-770.

Rainayee, R. 2012. Organization, job, perks, and employee turnover intentions. Journal of Research in Management \& Technology, 1, 17-21.

Ramonienè, L., Gorbatenko, O. 2013. Managing occupational stress in human service nonprofit organizations in Mykolaiv, UK INE. Organizations and Markets in Emerging Economies, 64-96.

Rizwan, M., Mukhtar, A. 2014. Preceding to employee satisfaction and turnover intention. International Journal of Human Resource Studies, 4(3), 87.

Saeed, I., Waseem, M., Sikander, S., Rizwan, M. 2014. The relationship of turnover intention with job satisfaction, job performance, leader member exchange, emotional intelligence, and commitment. International Journal of Learning \& Development, 4(2), 2164-4063.

Selye, H. 1976. The stress of life. New York: McGraw-Hill.

Skinner, N.J., Chapman, J. 2013. Work-life balance and family friendly policies. Doctoral Dissertation, ANZSOG-The Australia and New Zealand School.

Soelton, M., Lestari, P.A, Arief, H., Putra, R.L. 2020. The effects of role conflicts and burn out toward turn over intention at software industries, work stress as moderating variables. Advances in Economics, Business and Management Research, 120, 185-190.

Steel, R.P., Lounsbury, J.W. 2009. Turnover process models: review and synthesis of a conceptual literature. Human Resource Management Review, 19(4), 271-282.

Tabachnick, B.G., Fidell, L.S. 2007. Using multivariate statistics (5th ed.). New York: Allyn and Bacon. 
Tongchaiprasit, P., Ariyabuddhiphongs, V. 2016. Creativity and turnover intention among hotel chefs: The mediating effects of job satisfaction and job stress. International Journal of Hospitality Management, 55, 33-40.

Wani, S.K. 2013. Job stress and its impact on employee motivation: A study of a select commercial bank. International journal of business and management invention, 2(31), 13-18.

West, L.S. 2007. Examining the Relationship between Employee-Superior Conflict and Voluntary Turnover in the Workplace: A Comparison of Companies across Industries, University of North Texas.

Zhang, G., Lee, G. 2010. The moderation effect of perceptions of organizational politics on the relationship between work stress and turnover intention: An empirical study about civilian in skeleton government of China. iBusiness, 2, 268-273.

Ziedelis, A. 2019. Associations between psychological work environment factors with work engagement and burnout in Nursing. Journal of Organizations and Markets in Emerging Economies, 59, 53-67. Doi:10.15388/Psichol.2019.4. 